\title{
Morgan Watkins
}

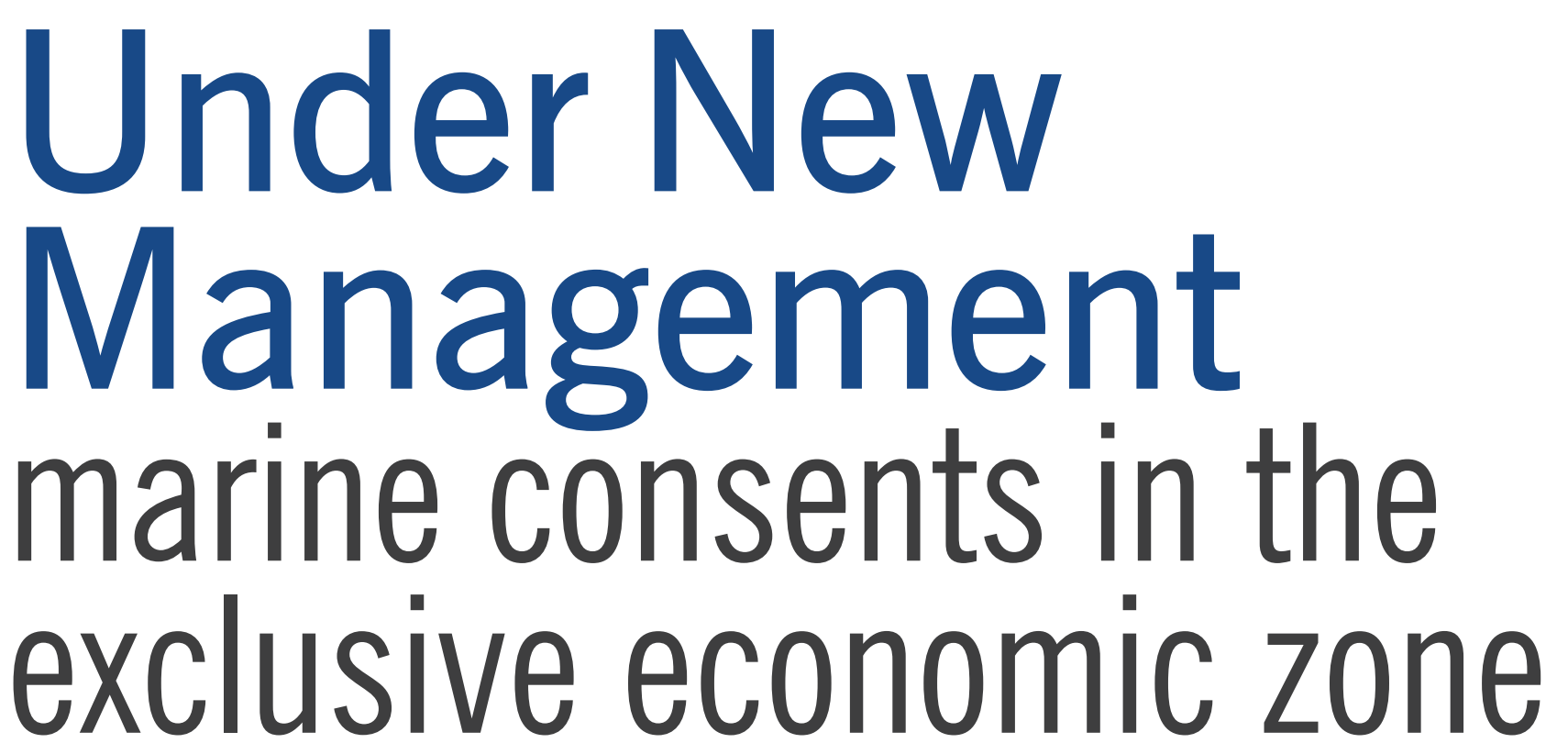

Under any system of regulation, the quality of the decision
makers and trust in their competence and integrity is a
paramount factor.

Introduction

Mineral resources and energy are central to the level of technological sophistication that we have come to expect in our everyday lives. Yet the availability and use of these finite resources is unsustainable, almost by definition, and particularly so when considering fragile ecosystems. This raises the 'super-wicked' policy issue, negotiated through resource management legislation, of trying to balance

Morgan Watkins is a graduand of the Bachelor of Laws with Honours from Victoria University of Wellington. This article was written in partial satisfaction of that degree. Morgan would like to acknowledge Catherine lorns for her helpful comments on drafts of this article. The views expressed in this article are his own and do not reflect the views of any employer, past or present. necessary resource use with not irreparably damaging the natural environment (Levin et al., 2012).

This article primarily concerns the effects of the Resource Legislation Amendment Bill (2015) on management of the exclusive economic zone (EEZ) and continental shelf area. Omnibus bills that contain nontechnical and contentious amendments continue to challenge civil society's ability to fully consider the implications of reform. Despite that limitation, the 
government strengthens requirements for marine dumping and disposal consents contrary to fears expressed in some select committee submissions. It also argues that management powers will be further concentrated in the responsible minister by implementing a board of inquiry process for marine consents, building on already extensive regulatory powers in the EEZ and continental shelf area. Although its effects are mixed, the bill may be a retrograde step for genuinely consistent, sustainable management of the marine environment, as too much will depend on the government of the day.

\section{Legal and economic context}

Possessing sovereign rights over the EEZ and continental shelf area to seabed mineral resources, among other things, New Zealand is effectively obliged to
Convention on the Law of the Sea (1982) and the Convention on the Prevention of Marine Pollution by Dumping of Wastes and Other Matter (the London Convention, 1972). ${ }^{1}$ Section 12 protects certain Māori interests by emphasising aspects of the act which concern Treaty of Waitangi interests in EEZ and continental shelf area. Generally, sections 10-12 of the act roughly analogise with the 'heart' of the Resource Management Act 1991 (RMA) as contained in sections 5-8 (Grant, 2015, p.40).

Recent applications for seabed mining consents by Trans-Tasman Resources and Chatham Rise Phosphate have stimulated public interest in the marine consent regime. $^{2}$ As the EEZ Act mandates a precautionary approach $(s 61(2))$, both applications were rejected largely because of their uncertain environmental effects.

\section{Omnibus bills are frequently complex in nature, with many consequential amendments, and are thus typically less likely to meet the exacting standards of quality that we should expect.}

implement a marine consent regime. Extra-territorial seabed mining is currently governed by the Environmental Protection Authority (EPA), under the Exclusive Economic Zone and Continental Shelf (Environmental Effects) Act 2012 (EEZ Act). The EEZ Act applies from the edge of the territorial sea (12 nautical miles from the low tide mark) to 200 nautical miles from shore and, beyond that, where a continental shelf factually exists to a maximum distance of 350 nautical miles (Salmon and Grinlinton, 2015). New Zealand's marine estate is over six million square kilometres in size.

The EEZ Act's purpose is to 'promote the sustainable management of natural resources' in the exclusive economic zone and continental shelf area (s10). It 'continues' implementation of $\mathrm{New}$ Zealand's international marine obligations: notably, the United Nations
From a perspective of promoting sustainable management, this suggests the act is working.

\section{Resource Legislation Amendment Bill}

The Ministry for the Environment states the Resource Legislation Amendment Bill amends the EEZ Act to maintain the current balance between enabling economic activity and protecting environmental features, while reducing regulatory burdens on regime users (Ministry for the Environment, 2015, p.9). In particular, it seeks to avoid costs disproportionate to likely environmental harms from proposed activities. Main amendments include: strengthening of information requirements for marine waste consents; new ministerial powers to make EEZ policy statements, which consent authorities must have regard to; and a change in the marine consent process for notifiable activities under section 20 from an EPA assessment to a proposed board of inquiry process (Resource Legislation Amendment Bill, explanatory note). These amendments seek to harmonise the EEZ Act process with the RMA process as much as possible. Later parts of this article address the cumulative effects of these amendments.

Procedurally, the Resource Legislation Amendment Bill is disappointing. Omnibus bills should not be used for contentious, non-technical amendments (Watkins, 2016). They suppress meaningful debate in a manner that is analogous to the overuse of urgency, by giving MPs and civil society a comparatively large amount of information to review in a shorter period of time. This is why omnibus bills were, historically, typically reserved for implementing non-contentious amendments. ${ }^{3}$

Environmental policy matters are hotly contested by non-governmental organisations and industry representatives. To illustrate, this bill received hundreds of submissions at select committee. Substantial, sustained controversy around the bill's effects on the RMA wrenches scrutiny away from the EEZ and continental shelf to land resources instead. The distraction is enough to raise the question of whether the bill, notwithstanding its policy goals, misuses the omnibus procedure. A standalone bill would have been preferable because it would improve the transparency and publicness of EEZ reform.

The point is not purely academic. Overuse of omnibus legislation can lead to technical mistakes, which may have disproportionately consequential effects. For example, the EPA is required under section $45(1)$ (c) to directly notify iwi of consent applications that affect their interests 'in order to recognise and respect' the Crown's treaty obligations (EEZ Act, s12). Awkwardly, section 45 was repealed in the initial draft. Were the obligation not re-enacted (clause 188, proposed section 47(1)(b)(ii)), the Crown could conceivably have fallen short of the behaviour expected of a model treaty partner. Section 12's reference to a section that will no longer exist but whose content is preserved elsewhere is a minor technical 
error that was corrected at select committee. Nonetheless, this error demonstrates that mistakes can and do arise through inadequately scrutinised amendment procedures. Not all will be harmless or noticed in a timely fashion.

The bill's omnibus nature limits the extent to which changes to the marine consent regime face adequate public and parliamentary scrutiny. Omnibus bills are frequently complex in nature, with many consequential amendments, and are thus typically less likely to meet the exacting standards of quality that we should expect. These two factors mean omnibus amendment procedures are not to be preferred for contentious programmes of reform.

\section{Regulating marine wastes}

This article has been written in part because some submitters at select committee argued that the bill's change to the definition of dumping would loosen domestic requirements for marine dumping consents, in violation of the London Convention and the Convention for the Protection of the Natural Resources and Environment of the South Pacific Region (Nouméa Convention, 1990). ${ }^{4}$ However, New Zealand's domestic regulation meets international obligations and appears to be strengthened by the bill, especially in relation to adaptive management and decommissioning offshore installations.

\section{International marine waste obligations}

Signatories to the London Convention's 1996 protocol, including New Zealand, are obliged to ban unauthorised dumping and may choose to consent to dumping of certain 'Annex 1 materials' - relevantly, 'inert, inorganic geological material' that is not radioactive (London Convention, annex 1). Consents must meet certain requirements under annex 2. The EEZ Act bans dumping and disposal and regulates marine consents. Therefore, the government initially appears to meet its obligations to prevent and reduce dumping. To show otherwise would require arguing that the consent regime is defective by, for example, not adequately assessing environmental impacts in terms of the convention. This argument was not advanced in the selection of submissions reviewed and would require specific and in-depth evaluation.

General prohibitions of dumping and discharges are not amended. The bill merely alters the definition of 'dumping' to reflect the protocol's definition, rather than the original definition (cause 184). Additionally, the London Convention explicitly excluded seabed mineral mining wastes from the definition of 'dumping' from the beginning. Accordingly, the Exclusive Economic Zone and Continental Shelf (Environmental Effects - Discharge and Dumping) Regulations 2015 have regulated seabed mineral mining wastes as 'discharges' at least since February 2014 (regulations 7-11). Discharges from
Convention by only banning dumping of harmful substances, which is less restrictive than the 1996 protocol's general ban on dumping. This is to be expected given that the Nouméa Convention predates the protocol, but it also shows that suggestions that the Nouméa Convention treats dumping more stringently than the EEZ Act regime does are not sustainable.

In this light, New Zealand's regulatory regime seems to comply with the Nouméa and London conventions. Although the bill would have understandably looked concerning to interested members of the public, more direct consideration suggests that allegations that it breaches $\mathrm{New}$ Zealand's obligations under the

\section{Adaptive management is a form of management ethic designed to overcome inadequate information by permitting novel activities to proceed under intense scrutiny ...}

industrial mining continue to be defined as discretionary activities in regulations, meaning that a marine discharge consent is still required (regulations 10,33).

It is not legally significant that the Nouméa Convention's definition of 'dumping' fails to include the exemption of seabed mining wastes included in the London Convention (article 2(b)). The Nouméa Convention explicitly regulates seabed mineral exploitation in article 8, which only creates an obligation to 'take all appropriate measures to prevent, reduce and control pollution' caused by seabed mining. Taken with the provision that the Nouméa Convention is not intended to alter interpretation of the London Convention (articles 4-5), article 8's relatively permissive obligation is likely satisfied by the EEZ Act and an attendant precautionary approach.

Article 8's existence in itself suggests seabed mining wastes are not captured by article 10's ban on the dumping of harmful substances. Further, article 10 gives effect to the 1972 London conventions are not credible, at least on the reviewed arguments advanced before the select committee.

\section{Regulation of marine wastes improved}

Ecological sustainability requires understanding the consequences of human activity. This observation underpins the EEZ Act's information principles, supporting the precautionary principle. The act's information principles and precautionary approach constitute the 'mind' of our marine consent regime (Grant, 2015, p.40).

The EEZ Act presently requires consent authorities, when refusing consents by reason of inadequate information as to environmental effects, to consider whether applying adaptive management principles would allow the activity to begin (s61(3)). Adaptive management is a form of management ethic designed to overcome inadequate information by permitting novel activities to proceed under intense scrutiny (s4(2)). The bill will continue to exclude adaptive 
management principles from the consideration of marine dumping and disposal consents (clause 195). ${ }^{5}$

Removing adaptive management practices strengthens precaution by requiring applicants to demonstrate in advance, with sufficient evidence, that proposed activities will have limited environmental consequences. It is appropriate to require that one-off or similarly limited activities be justified on their faces because, unlike more prolonged activities, the prospect for monitoring ongoing environmental effects through adaptive management is restricted.

Despite being reorganised, the bill retains the requirement that an application for a dumping permit must be refused if the waste can be reused, recycled or dumping regulations are the primary, currently existing environmental requirements governing decommissioning of offshore installations.

Currently the government has no power to force decommissioning of an installation (Ministry for the Environment, 2015, p.21). If a marine dumping consent were rejected for whatever reason, installation owners could theoretically 'fake' the continued operation of the rig. This enables operators to avoid compliance with environmental standards. Current applicable penalties are too low, compared to the potentially massive costs of decommissioning, to incentivise compliance (ibid., pp.21-3). Fortunately the bill rectifies this regulatory gap by

\section{Because disposal of wastes is integral to mining operations, applications for marine disposal consents will be heard by boards of inquiry while considering the main marine consent ...}

treated in a way that does not have a more than minor effect on human health or cost more than the consent authority considers reasonable, or if the consent authority believes dumping is 'not the best approach' to waste disposal (clause 193). This may suggest, rather than approaching marine wastes from perspectives endorsing 'weak sustainability', a continued sensitivity in the overall scheme of the EEZ Act to the idea that 'environmental capital' and financial capital are not fully interchangeable.

Further, new requirements for offshore installation operators to prepare decommissioning plans will be captured by the above changes to dumping rules (clause 217). Laws of the sea already permit offshore installation structures to be dumped (abandoned) provided that navigation of the seas and other similar matters are not infringed (United Nations Convention on the Law of the Sea, article $78(2))$. Subject to these requirements, requiring decommissioning plans, requiring plans to comply with applicable regulations, and requiring owners to actually apply for consents for any discretionary activities included within the plans. Thus, the bill ensures that owners of installations can be compelled by government to meet their legal obligations at the end of an installation's life. Stewardship of the marine environment is notably enhanced.

\section{Overall assessment}

Although some changes to the marine wastes regime arguably cut both ways, the bill strengthens environmental protection. In particular, marine waste consents should be more difficult to obtain. However, neither the regulatory impact statement nor the explanatory note of the bill emphasise this change in environmental policy. Full and effective regulatory impact statements are important because they enable civil society and parliamentarians to undertake due diligence before participating in the legislative process. It may turn out that the analysis was incomplete or in some other way unsatisfactory for this educative purpose.

Possibly these amendments are mere clarifications of the existing intended position under the EEZ Act, but a failure to seize potential political capital seems odd. Because disposal of wastes is integral to mining operations, applications for marine disposal consents will be heard by boards of inquiry while considering the main marine consent. $^{6}$ A potential explanation for this silence is that the government anticipates that boards of inquiry, guided by ministerial policy statements, will be less stringently protective of the environment despite apparently more onerous legal considerations.

\section{Marine consent process new, not necessarily improved}

Clause 188 of the bill replaces sections 35-58 of the current EEZ Act regime. In particular, it provides that consent applications for publicly notifiable activities otherwise prohibited by section 20 are to be heard by boards of inquiry (clause 188, proposed sections 53-8). Boards are composed of three to five members, appointed by the minister (proposed section 53). Boards replace the EPA in substantive decisions on such applications, with the intention to harmonise marine consents with the RMA's scheme for 'projects of national significance' (explanatory note).

Non-notified activities, defined in regulations under the act, will still be determined by the EPA (proposed sections 51-2). However, non-notifiable consents relating to notifiable consents (for example, disposal of mining wastes stemming from mining operations covered by section 20) would be heard by a board when considering a notifiable consent (proposed section 45). This avoids a situation where, for example, a board permits a mining operation but the EPA does not permit associated waste disposal.

All section 20 activities are publicly notifiable unless regulations provide otherwise (EEZ Act, ss20, 29D). However, 
not every marine activity captured by section 20 of the EEZ Act is likely to be significant in its effects. Even industry partners are concerned by the breadth of the new process's application and its potential to raise costs for noncontentious section 20 consent applications (Petroleum Exploration and Production Association of New Zealand, 2016, p.7). This suggests that the board of inquiry model may be miscalibrated in its scope. Alternatively, the responsible minister may intend to increase the number of activities deemed nonnotifiable, but this would be to exclude public participation in the consent process. Neither option is ideal.

In the light of industry concern, scepticism about the bill's aims is justified. If boards of inquiry come to decisions otherwise identical to an independent EPA's, then the differentiation must be by cost. Yet cost is presumably tied to the processes which confine decision makers rather than to their identities. If the problem with the status quo is cost, it is not clear a board of inquiry will be inherently cheaper than consideration by the EPA. Implementing a process the minister will have more control over, rather than simply 'fixing' the EPA's process, suggests that more ministerial control - resulting in substantively different decisions - is one of the bill's true aims.

This intention to centralise power is demonstrated by introducing sections 37A-G, which create a planning tool called an 'EEZ policy statement' (proposed sections 37A-G). Section 37C outlines mandatory relevant considerations for issuance of a policy statement; namely:

(a) the actual or potential effects of the use, development, or protection of natural resources; and

(b) New Zealand's obligations under any international conventions that relate to the marine environment; and

(c) the matters in subpart 2 of Part 1; and

(d) any submissions received on the proposed EEZ policy statement; and

(e) any other matter that the Minister considers relevant.

Subsection (c) is referring to sections 10-12 of the EEZ Act, the 'heart' of the regime. Despite some concerns expressed at select committee by the Environment and Conservation Organisations of New Zealand (Environment and Conservation Organisations of New Zealand, 2016, p.21), nothing whatsoever is affected by the fact that the minister merely 'may' (rather than 'must') have regard to these considerations when conducting initial policy work on EEZ policy statements (proposed section 37A). An elected government has the privilege to determine their own policy agenda free of legal fetters, so different treatment between sections $37 \mathrm{~A}$ and $37 \mathrm{C}$ is manifestly justifiable. Section 37C sets hard obligations on the executive before policy
Environment, 2015, pp.52-4). With an arguably applicant-focused record, whether the minister and Ministry for the Environment will be seen as good custodians of non-industry interests after the bill is passed is an open question. If not, the new regime will not inspire confidence among environmental and other community groups or iwi.

Being able to trust the executive is especially important because the purpose of EEZ policy statements is to state objectives and policies to 'support decision-making on applications for marine consents' (proposed section $37 \mathrm{~A}(1))$. This purpose is narrower than its

\section{As protection of the seabed has been vigilant to date, one possible interpretation of the proposed reforms is that the bill is designed to massage decisions more favourable to industry.}

statements will have any planning effect (clause 190(6)). These are legally binding criteria for executive discretion, and bring a needed additional degree of certainty into the consent process for applicants (Resource Management Law Association, 2016, p.315).

However, '[u]nder any system of regulation, the quality of the decision makers and trust in their competence and integrity is a paramount factor' (Palmer, 2013, p.145); ministerial control over the policy statement process could therefore be more concerning to some. Ministers determine processes for issuing policy statements, provided 'adequate time and opportunity' is allowed for comments from those affected (proposed section $37 \mathrm{~B})$. The bill gives wide discretion. It is non-prescriptive about the process, suggesting limited prospects for judicial review oversight. Moreover, it is unclear that an expedited process will involve adequate consultation with iwi. ${ }^{7}$ Similarly, it is instructive that the Ministry for the Environment consulted with industry and the EPA, but not community groups, when preparing the bill (Ministry for the
RMA cognate's focus on 'matters of national significance that are relevant' to statutory purposes (RMA, s45(1)). Because policy statements thus designed are effectively instructions to consent authorities, ${ }^{8}$ often minister-appointed boards, on how to approach decisions, that the minister makes effective policy without also overreaching is critical.

While the 'heart' and 'mind' of the EEZ Act regime are relatively unamended by the bill, introducing boards of inquiry and EEZ policy statements will hand increasing power of the 'limbs' to sitting governments (Grant, 2015, p.40). Three key features of the current regime are public participation in the consenting process, comprehensive and impartial consideration of matters under section 59 when granting consents, and the removal of power from the minister to the EPA (Palmer, 2013, p.142-5). Each feature, but particularly the last, is pared back by the bill.

When trying to determine the effects of this bill, a lot depends on the specific minister responsible for sustainable management of the EEZ. But, as above, 
the minister may be tempted to regulate to make more section 20 activities nonnotifiable, to issue potentially intrusive policy statements to force certain consenting outcomes, and to stack boards of inquiry with like-minded decision makers. These are all reasons the EPA is the presently responsible consent authority. In a context requiring rapid protection of the environment, it is perhaps undesirable in principle to expose marine consents to political contestation that will limit sustained action. Allowing EEZ management to be tied so closely to governmental objectives may destabilise cross-party consistency in the marine management regime. Such exposure would mark a sea change in policy settings which may be seen as sufficient to undermine the EEZ Act's scheme.

\section{Conclusion}

The net effect of the bill's amendments is difficult to precisely quantify in advance. There is a seemingly clear improvement in marine waste regulations, as outlined above. However, this may or may not be offset by increased ministerial control over consenting authorities and processes. Additional governmental control of the consenting regime undermines at least one key feature of the status quo, and potentially others if ministerial authority is eagerly exercised. The precise effects depend on the minister in question.

As protection of the seabed has been vigilant to date, one possible interpretation of the proposed reforms is that the bill is designed to massage decisions more favourable to industry. The EPA held that rejecting applications by Trans-Tasman Resources and Chatham Rise Phosphate was exactly what sustainable management demanded because adaptive management practices were inadequate at the time to mitigate unknown environmental costs. That position was defensible and the applicants had the right to resubmit their applications with updated proposals if they disagreed. If these decisions spurred the present reforms, leaving aside questions of economic value, then to see a functioning statutory regime undermined might not suggest to casual observers that sustainable management will be protected by these reforms. If so, it is fair to ask whether the best interests of the exclusive economic zone and continental shelf area are indeed served by this bill.

\footnotetext{
Convention on the Law of the Sea, opened for signature 10 December 1982,1833 UNTS 397 (entered into force 16 November 1994); Convention on the Prevention of Marine Pollution by Dumping of Wastes and Other Matter, opened for signature 29 December 1972, 1046 UNTS 138 (entered into force 30 August 1975).

2 The decisions on their applications can be found on the Environmental Protection Authority's website.

3 The standing orders of the House of Representatives 2014 contemplate omnibus bills as part of a wider reform programme (SO 263), but see Geoffrey Palmer as cited in Dinsdale, 1996, p.19.

4 Convention for the Protection of the Natural Resources and Environment of the South Pacific Region, adopted 24 November 1986, [1990] NZTS 22 (entered into force 22 August 1990).

5 See the article in this issue of Policy Quarterly, 13 (2), pp.10-16 on this topic by Catherine lorns and Thomas Stuart.

6 Clause 188, at proposed section 45. The current application by Trans-Tasman Resources Limited for both a marine (activity) consent and a marine discharge consent for seabed ironsands mining illustrates this requirement: see epa.govt.

7 See generally concerns expressed in the Te Ātiawa o Te Waka-a-Māui Trust's submissions to the local government and environment select committee.

8 Straterra sees them as such: see their submission to the committee, p.19.
}

\section{References}

Dinsdale, J. (1996) 'Law making under MMP: the legislative process and the new standing orders', LLM research paper, Victoria University of Wellington

Environment and Conservation Organisations of New Zealand (2016) 'Submission to the Local Government and Environment Committee on Resource Legislation Amendment Bill 2015', 7 April

Grant, M. (2015) 'Sustainable management: a sustainable ethic?', in T. Daya-Winterbottom (ed.), Frontiers of Resource Management Law, Wellington: Brookers

Levin, K., B. Cashmore, S. Bernstein and G. Auld (2012) 'Overcoming the tragedy of super wicked problems: constraining our future selves to ameliorate global climate change', Policy Sciences, 45 (2), pp.123-52

Ministry for the Environment (2015) Regulatory Impact Statement: Resource Legislation Amendment Bill 2015 (EEZ Amendments), Wellington

Palmer, K. (2013) 'Environmental management of oil and gas activities in the exclusive economic zone and continental shelf of New Zealand', Journal of Energy and Natural Resources Law, 31 (2), pp.123-46
Petroleum Exploration and Production Association of New Zealand (2016) 'Submission to the Local Government and Environment Committee on Resource Legislation Amendment Bill 2015', 31 March

Resource Management Law Association (2016) 'Submission to the Local Government and Environment Committee on Resource Legislation Amendment Bill 2015', 31 March

Salmon, P. and D. Grinlinton (eds) (2015) Environmental Law in New Zealand, Wellington: Thomson Reuters

Straterra Inc (2016) 'Submission to the Local Government and Environment Committee on Resource Legislation Amendment Bill 2015', 31 March

Te Ātiawa o Te Waka-a-Māui Trust (2016) 'Submission to the Local Government and Environment Committee on Resource Legislation Amendment Bill 2015', 31 March

Watkins, M. (2016) 'Proceed with caution: law reform, judicial review and the Judicature Modernisation Bill', Victoria University of Wellington Law Review, 47, pp.149-71 